\title{
Tour Route Multiobjective Optimization Design Based on the Tourist Satisfaction
}

\author{
Yan Han, Hongzhi Guan, and Jiaying Duan \\ Key laboratory of Traffic Engineering, Beijing University of Technology, Beijing 100124, China \\ Correspondence should be addressed to Yan Han; hanyan422@bjut.edu.cn
}

Received 20 September 2013; Accepted 4 December 2013; Published 8 January 2014

Academic Editor: Huimin Niu

Copyright (C) 2014 Yan Han et al. This is an open access article distributed under the Creative Commons Attribution License, which permits unrestricted use, distribution, and reproduction in any medium, provided the original work is properly cited.

The question prompted is how to design the tour route to make the tourists get the maximum satisfactions considering the tourists' demand. The influence factors of the tour route choices of tourists were analyzed and tourists' behavior characteristics and psychological preferences were regarded as the important influence factors based on the tourist behavioral theories. A questionnaire of tourists' tour route information and satisfaction degree was carried out. Some information about the scene spot and tourists demand and tour behaviors characteristic such as visit frequency, number of attractions visited was obtained and analyzed. Based on the convey datum, tour routes multiobjective optimization functions were prompted for the tour route design regarding the maximum satisfaction and the minimum tour distance as the optimal objective. The available routes are listed and categorized. Based on the particle swarm optimization model, the priorities of the tour route are calculated and finally the suggestion depth tour route and quick route tour routes are given considering the different tour demands of tourists. The results can offer constructive suggestions on how to design tour routes on the part of tourism enterprises and how to choose a proper tour route on the part of tourists.

\section{Introduction}

With the development of economics, more and more people have leisure time to travel. During the travel, it is necessary for the tourist to determine the travel destination and traffic mode and visit more scenic spots and historical sites in the limited time budget and get the maximum satisfactions. For some tourists, it will take them some time to determine the tour route before or during the travel [1], especially for those tourists who visit the scenic spot for the first time. So for tourism enterprises the most important thing is to provide reasonable tour route and different scenic spots to attract more tourists and enhance the attractions charm and popularity. More and more tour route products are analyzed and provided so as to meet the different demands of tourists. And the problem prompted for the tourism enterprises is how to design and provide the tour route system to make the tourists get the maximum satisfactions according to the tourists' demand, what the tourists' demand is, and how to obtain the tourists' demand. The tour route system refers to the continuous space chain connected with each landscape feature point of a tourist area with the concepts of time and space. It has three different levels: one is accessibility tourism routes connected by several tourist center cities; the second is the main tourist routes in which the tourist center of the city is defined as a "home base" and various tourist scenic spots are links to the tourist center of the city; the third is tour route within the scenic which is discussed in this paper [2].

The design of tour route is associated with the development of Chinese tourism academic research and is divided into three categories. One is from space research, mainly focused on the characteristics and evolution of the spatial structure of the tourist destination. The second is from an economic point of view to solve tourists' destination choice decision problem among multiple destinations with microeconomic method to obtain the greatest satisfaction during the tour. The third is studied on operational research; for example, Tang Li-fan proposed the optimal tourist trails system design method based on graph theory. Domestic and foreign scholars have found that the trails system organizations play an important role in the whole travel process and begin to explore the best mode such as Campbell mode [3], StewartVogt multidestination travel mode [4], Lundgren mode [5], and Jigang and Yifang mode [2]. It can be concluded that 
the recent route research mainly focuses on regional scale instead of microscale study such as scenic internal travel route design. Some route designs still stay at the conceptual level and lack maneuverability. As personalized trend is increasingly evident, every tourist has its own psychological preferences and demand so that the same travel route design cannot meet all tourists' demand. So the tour route design should be given to make the tourists get the maximum satisfactions considering psychological preferences of tourists. It is very necessary for us to obtain the tourists' satisfaction degree and analyze the relationship between the tourists' satisfaction degree and travel route choice behavior to enhance the travel behavior models.

To get the reasonable tourism organization mode, the tour routes organization model of the domestic and foreign is summarized and evaluated. Considering the influence of tourists' behavior characteristics and psychological preferences, tourist routes optimal model based on multiobjective optimization function is prompted.

\section{Behavioral Theories}

This section discusses behavioral theories that may explain the dynamics in satisfaction. How do people evaluate their satisfaction? Judgments of satisfaction are influenced by the available information and by the heuristics people use at the time of making these judgments [6-10]. They present a model showing the influence of mood and comparison processes on satisfaction evaluations. Three types of comparison processes have been discussed in the literature: comparison to self, comparison to others, and counterfactuals [11].

Comparison to self involves comparing one's present situation with one's previous situation or predicted future situation. Tourists feel different ratings of satisfaction for each attraction which involves comparing one attraction with another attraction or comparing satisfaction of this tour with that of one's previous tour experience. Perceived improvements in one's situation (e.g., better health, etc.) will lead to the increases in ratings of satisfaction, but it is limited by changing aspiration levels and adaptation effects. Comparison to others (or social comparison) is the most popular type of comparison discussed and involves comparing one's own situation to that of a comparison group. People make judgments about satisfaction degree based on whether one is better (downward comparison) or worse (upward comparison) than others. Finally, counterfactuals refer to comparisons of one's current situation with hypothetical situations that did not happen but could have happened and making judgments accordingly.

Thus, comparison processes involve reference points which are used as the basis of judgment. In prospect theory, reference points are used as the basis of evaluation of outcomes; outcomes that are better than the reference point (e.g., larger monetary value) are perceived as gains and those that are worse are perceived as losses [12]. A number of studies in the transportation field have attempted to explain route choice or mode choice using prospect theory and reference points. The effects of critical incidents on car users' predicted satisfaction with public transport were analyzed $[13,14]$. Also the influence of mood on satisfaction evaluations should be discussed. The congestion level of the attraction will affect the tourists' feeling and the attitude of the attraction. The more crowded the attraction is, the less satisfied the tourist feels.

In summary, in the context of the tour route experiment described in this paper, it may be postulated that when tourists are asked about their satisfaction with the total tour and each attraction, the information they used and the processes are different from those in operation after they have been "forced" to think about their options. After experimenting with suggested tour route applied by the tourism enterprises, they would gain new information and adjust any prior misperceptions about the tour. Therefore the tourists would be more aware of the options they have. Consequently, the measure of tour satisfaction is expected to be important.

\section{Influence Factors of Tour Route Design}

Tour space is divided into large, medium, and small scales. This paper puts forward basic principles of tour route design within small scale related to the tourists diversity of spatial behavior, whose route design is within the scenic area.

\subsection{Tourists Demand Diversification. The diversification of} tourists demand can be divided into two levels.

On the microlevel, tourists with different psychological characteristics have different travel motivations which can lead to different travel behavior. The behaviors of tourists are limited by the subjective conditions such as gender, age, national, psychological interest, ability, occupation, income, education level, social status, family structure, and residence conditions which may have different influences upon the spatial behavior of tourists $[15,16]$. Different tourists have different attitudes or perceptions of the same attractions. The tourists flow volume and direction in the different attractions are closely related to the level and visibility of the destination. Positive correlation exists between the attractions visibility and tourist accommodation, which lead to the tour route utilization being extremely uneven and the Gini coefficient being as high as 0.38 . So the satisfaction degree of the attractions is defined and asked about in the tourists' questionnaire.

The number and the tour order of the attractions are usually different for each tourist because of the diversification of tourists demand. And to evaluate the diversification of tourists demand, Tour Route Diversification Index is defined. The lager the Tour Route Diversification Index is, the bigger the diversification of tourists demand is.

On the macrolevel, the spatial behavior exhibited some regularity which depends on the travel destination features and traffic conditions.

3.2. Constraints Condition of Tour Route Design. The choices of the tour route are not only affected by the tourists' subjective view but also by the tour constraints condition such as economic constraints, physical constraints, and time constraints [16]. Economic constraints make tourist save 
the transport costs or the tickets cost during the choice of tour routes. Physical constraint makes tourist walk less and the number of the attractions visited during the tour is limited. Time constraints mean each tourist has a tour time budget and hopes to visit more attractions within the time budget and get the greatest satisfaction. At the same time, for each tourist, in order to complete the experience of the attractions, there should be a basic time guarantee in each attraction. The effective residence time for each attraction of the tour route is defined and investigated. The differences of the effective residence time at different attractions are caused by the characteristics of different tourists which lead to the diversification of tour route.

From the above, it can be concluded that, except for the diversification of tourist's demand, transport and tickets cost, physical constraint, tour time budget, number of attractions, and effective residence time are the important factors which will affect tourists' tour routes choice and must be considered during the tour route design.

\section{Tour Route Investigation and Analysis}

4.1. Survey Design and Implementation. The survey consisted of three parts: socioeconomic and demographic characteristics, travel behavior of tour route, and the demand and tour behavior characteristic of tourists.

In the first part, socioeconomic and demographic characteristics of tourists were interviewed such as gender, age, national, psychological interest, ability, occupation, income, education level, social status, family structure, and residence conditions which may have different influence upon the spatial behavior of tourists.

The subject of travel behavior of tour route was to get some information about the scene spot such as scenic type, expenditure, tour time, total number and spatial distribution of the attractions in scenic spots, number of attractions and effective residence time, visited order of the attraction, and so forth which can support datum sustain for tour route design.

The demand and tour behavior characteristic of tourists such as tour motivations and goals and tour time budget are collected. Finally the perception and experience of the tour such as the congestion level and satisfaction degree of the attractions and the revisit preference of the tourist are investigated.

The survey takes the mode of quiz face to face in the Dajue Temple in Beijing. The survey was conducted from April 15 2012 to May 20. A total of 60 respondents were obtained.

4.2. Analysis on Survey Results. This section presents descriptive findings from the experiment related to tourists' characteristics, tour route choice, perceptions and attitudes, and tour satisfaction.

Socioeconomic and demographic characteristics were summarized and analyzed. About half of the participants were male. The majority of participants were between 20 and 40 years old, with an average age of 43 years. The average size of the tourist was 3.1 and most of them are between 3 and 4. Moreover, the majority of participants had high income.

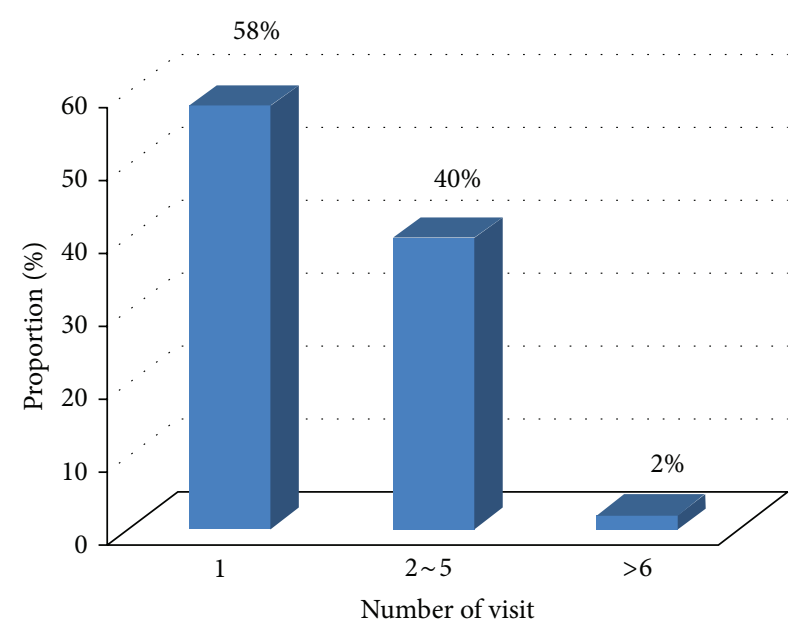

FIGURE 1: Number visit distribution.

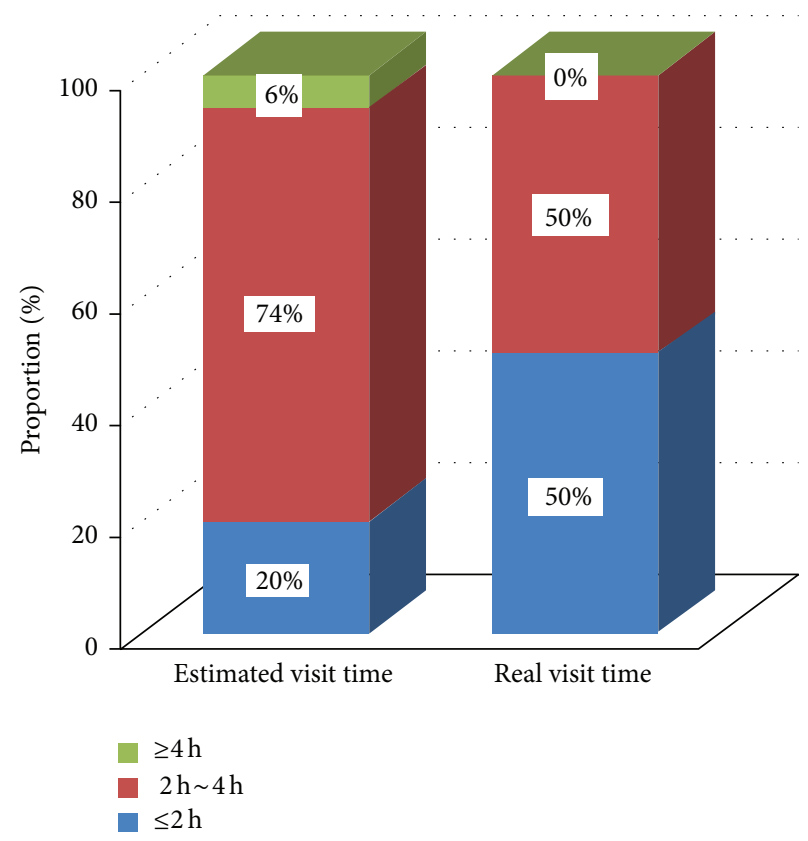

FIGURE 2: Comparison between tour budget time and real visit time.

25 percent of the participants had annual income greater than $¥ 100000$, and 10 percent of the participants did not report their income.

As shown in Figure 1, for 58 percent of the tourists it is the first time to visit Dajue Temple and about 40 percent of the tourists revisit Dajue Temple. Trip mode is interviewed and most of the tourists came to the Dajue Temple with private car and public transit.

Each tourist has his (her) own tour time budget. It is about 74 percent of the tourists whose estimated visit time is between 2 and 4 hours as shown in Figure 2. 50 percent of the tourists finished visiting Dajue Temple within 2 hours. Comparing the tour budget time with real visiting time, it can be concluded that for about 30 percent of the tourists their real visiting time is less than their tour budget time. 


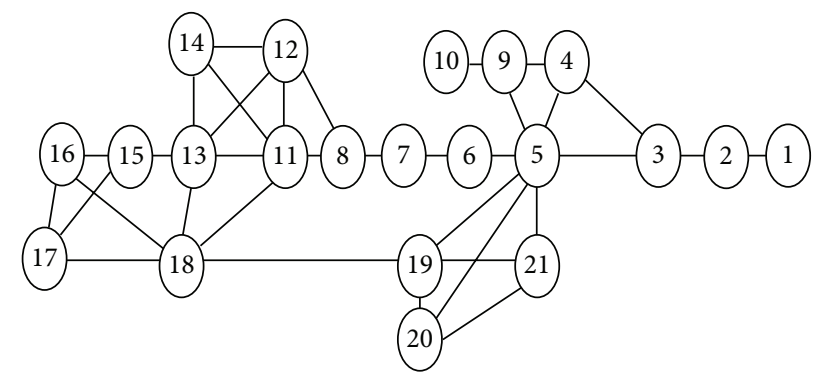

FIGURE 3: Distribution of the attractions of Dajue Temple.

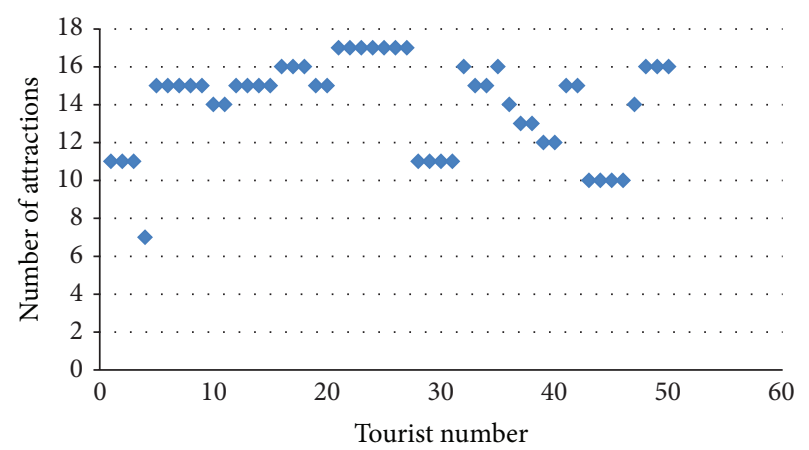

FIGURE 4: Number of attractions in tour route.

There are 21 attractions in Dajue Temple which is a famous temple and lies in the west of Beijing. The distribution of the attractions of Dajue Temple is listed in Figure 3. The total number of attractions which the tourists visited in their tour route is between 7 and 17 as shown in Figure 4. The total numbers of visited attractions by revisit tourist are less than the tourist for the first time. They will gain more satisfactions during the tour. Hence, during the tour route design, the tourist type should be considered. Numbers 6 and 3 as listed in Figure 3 are the famous attractions and all the tourists like to visit them. For some reasons such as the out-of-the-way of the attraction of the lack of traffic guilds some attractions are less visited.

Effective residence times of each attraction are gained. It can be given that most of the effective residence is between 5 and 20 minutes except 2 attractions and the average effective residence time is about 15 minutes as shown in Figure 5.

The main motivations of the tourists to Dajue Temple interviewed are as shown in Figure 6: "accompany the family, and friends" and "enjoy the scenery," accounted for $32 \%$ and $30 \%$, respectively; the purpose of physical exercise and relaxation accounted for $13 \%$ and $12 \%$, respectively; religious beliefs purposes accounted for only $8 \%$.

Measures of satisfaction with the attractions were obtained. Prior to the survey, participants rated their satisfaction on a 5-point scale anchored by "very dissatisfied" to "very satisfied," as a response to the following question: "taking all things together, how satisfied are you with the attraction?" The satisfaction degree of the attraction is defined to be between 1 and 5 . The higher the satisfaction degree of the attraction is, the better the tourists feel.

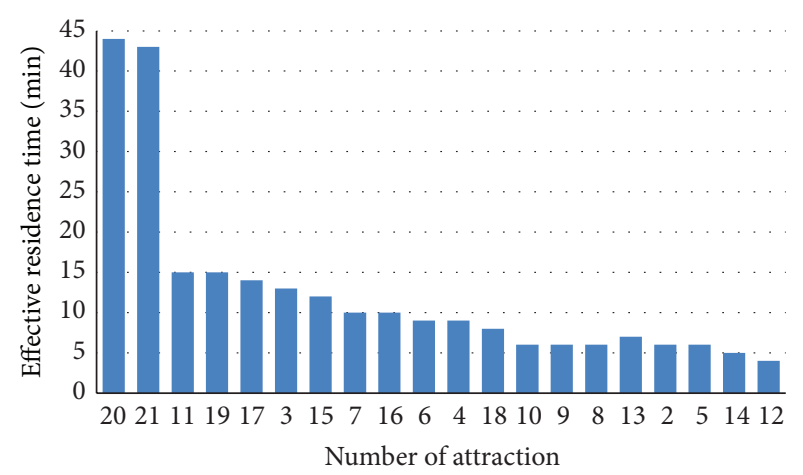

Figure 5: Effective residence time.

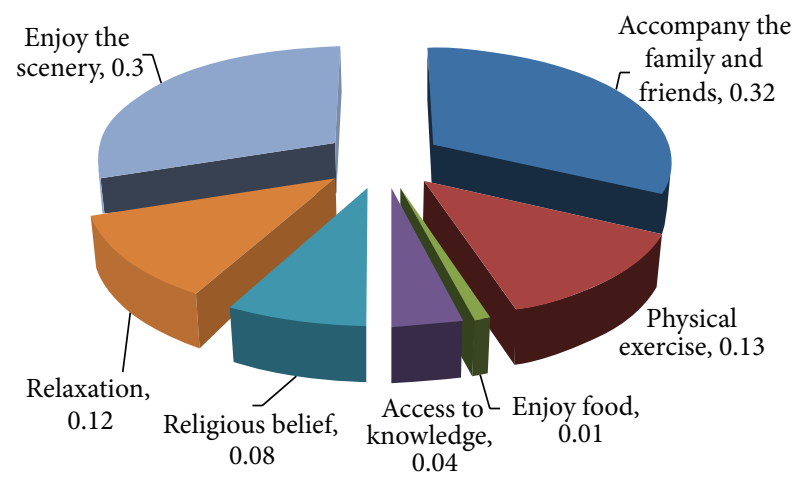

FIGURE 6: Motivation of the tourists.

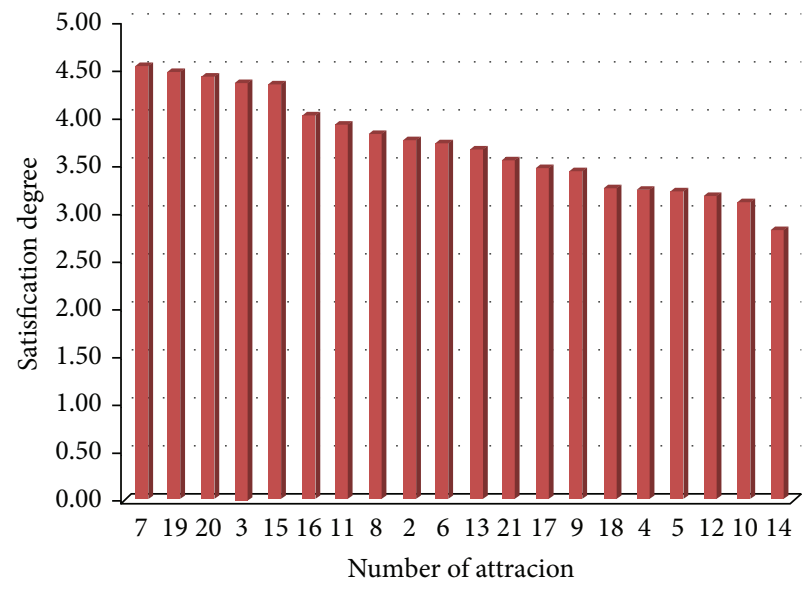

FIGURE 7: Satisfaction degree of attractions.

It can be concluded that the highest satisfaction degree of the attraction is Number 7 attraction which is 4.54 as shown in Figure 7 . The average satisfaction degree of the attraction is between 3 and 5 .

The relationship between the visit frequency of attraction and satisfaction degree and effective residence time and satisfaction degree are studied and listed in Figures 8 and 9. The results show that visit frequency and effective residence time and tourists attractions satisfaction are positively correlated with satisfaction degree of the attraction. The higher 


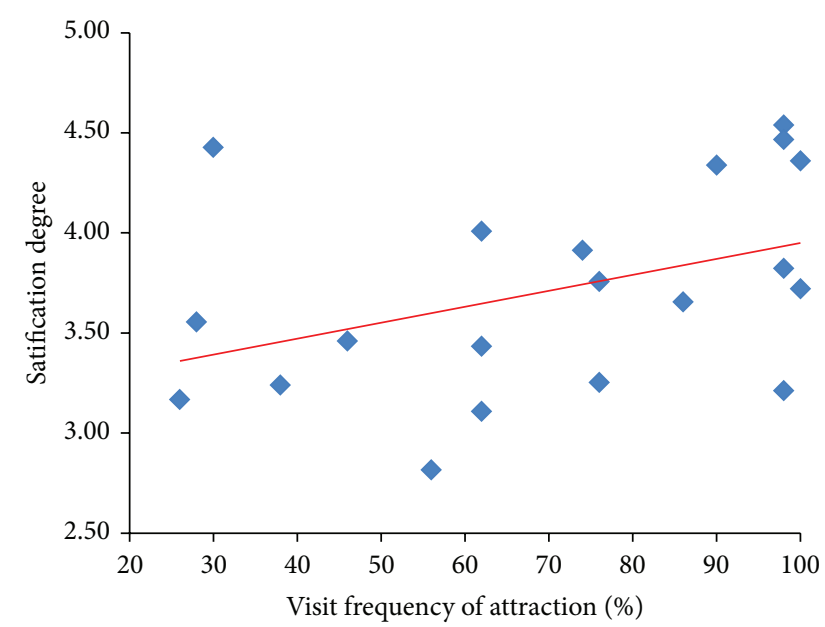

FIGURE 8: Visit frequency of attraction and satisfaction degree.

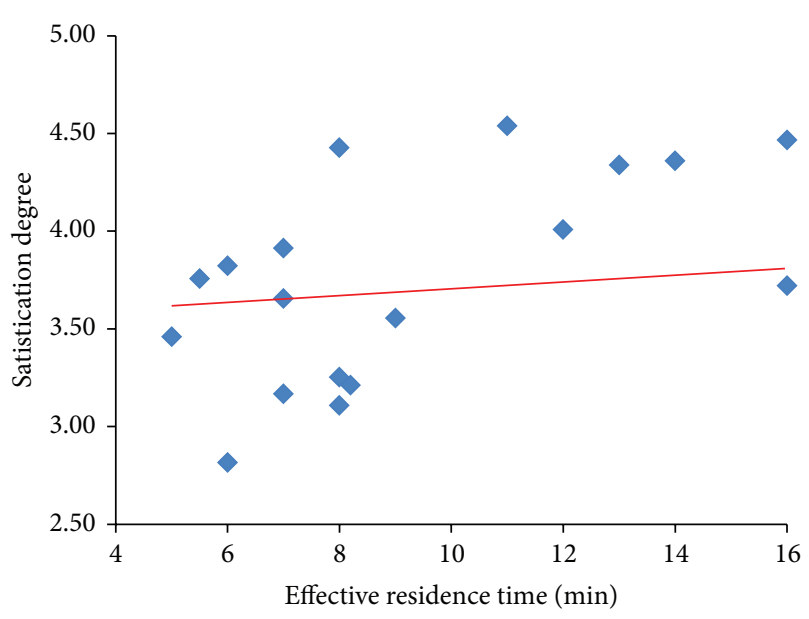

FIGURE 9: Effective residence time and satisfaction degree.

the satisfaction degree is, the more effective residence time is, and the higher the visited frequency of the attraction is.

\section{Tour Route Design Based on Multiobjective Optimization Model}

5.1. Multiobjective Optimization Model. During the tour, each tourist has a tour time budget and the tourists hope to visit more attractions within the time budget and get the greatest satisfaction. It can be concluded that optimal design of tour route is a multiobjective optimization procedure. The multiobjective optimization model is carried out for the tour route design. [17]:

Multiobjective optimization problem is listed as follows

$$
\begin{array}{r}
\min y=f(x)=\left\{f_{1}(x), f_{2}(x), \ldots, f_{n}(x)\right\}, \\
n=1,2, \ldots, N,
\end{array}
$$

$$
\begin{aligned}
& \text { s.t } g_{i}(x) \leq 0, \quad i=1,2 \ldots, m, \\
& h_{j}(x)=0, \quad j=1,2, \ldots, k \\
& x=\left\{x_{1}, x_{2}, \ldots, x_{D}\right\}
\end{aligned}
$$

where $x$ is the decision vector of $D, y$ is objective vector, $g_{i}(x)$ is the $i$ th inequality constraints, $h_{j}(x)$ is the $j$ th equality constraints, and $f_{n}(x)$ is objective function.

Two indicators are considered during the optimal design of the tourist routes. Optimized objective functions are described as follows:

$$
\begin{aligned}
& \operatorname{Min} \sum_{n} I_{E}^{i} \cdot x_{i}, \\
& \operatorname{Max} \sum_{n} I_{T}^{i} \cdot x_{i},
\end{aligned}
$$

where $x_{i}=1$ which means the $i$ th attraction is on the tour route and $x_{i}=1$ which means the $i$ th attraction is not on the tour. $I_{E}^{i}$ is the distance between $i-1$ th and ith attraction; $I_{T}^{i}$ is the satisfaction degree of the $i$ th attraction.

Because the tourists are more concerned with the satisfaction degree of the attraction during the optimal design of the tourist routes than the distance, the maximum satisfaction degree of the attraction is set as the first optimization objective and the minimum distance is set as the second optimization objective. The multiobjective optimization model is expressed as shown in

$$
\begin{aligned}
& \min z=P_{1}\left(d_{1}^{-}\right)+P_{2}\left(d_{2}^{+}\right), \\
& \text {s.t } \sum_{i} I_{T}^{i} \cdot x_{i}+d_{1}^{-}+d_{1}^{+}=E_{\max }, \\
& \sum_{i} I_{E}^{i} \cdot x_{i}+d_{2}^{-}+d_{2}^{+}=E_{\min } .
\end{aligned}
$$

In addition, according to the tourists demand, the constraint of the tour time and number of the visited attractions are listed as follows:

$$
\begin{aligned}
& 0<T \leq T_{\max } \\
& i_{\min } \leq i \leq i_{\max },
\end{aligned}
$$

where $P_{1}$ and $P_{2}$ are priority factors, $P_{1}$ is first priority factor, $P_{2}$ is second priority factor, $E_{\max }$ is the maximum satisfaction degree, $d_{1}^{-}$is the negative deviation value degree, $d_{1}^{+}$is the positive deviation value, $E_{\min }$ is the minimum length of tour route, $d_{2}^{-}$is the negative deviation value, and $d_{2}^{+}$is the positive deviation value.

\subsection{Calculation of the Multiobjective Optimization Model.} The level algorithm is carried out to calculate the multiobjective optimization model.

Step 1: optimizing the $P_{1}$ level in objective function

$$
\max z_{1}=d_{1}^{-} \text {. }
$$




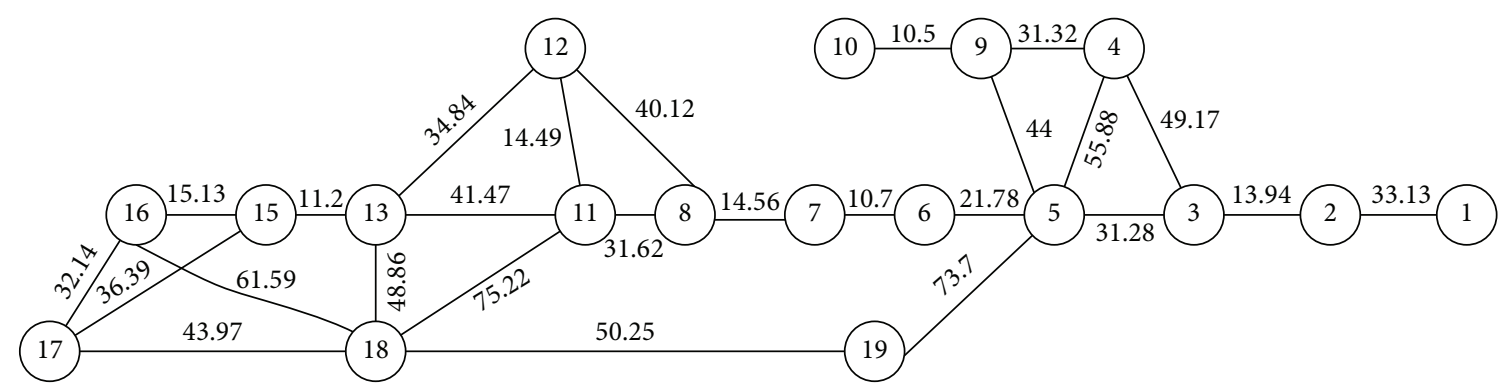

Figure 10: Distance.

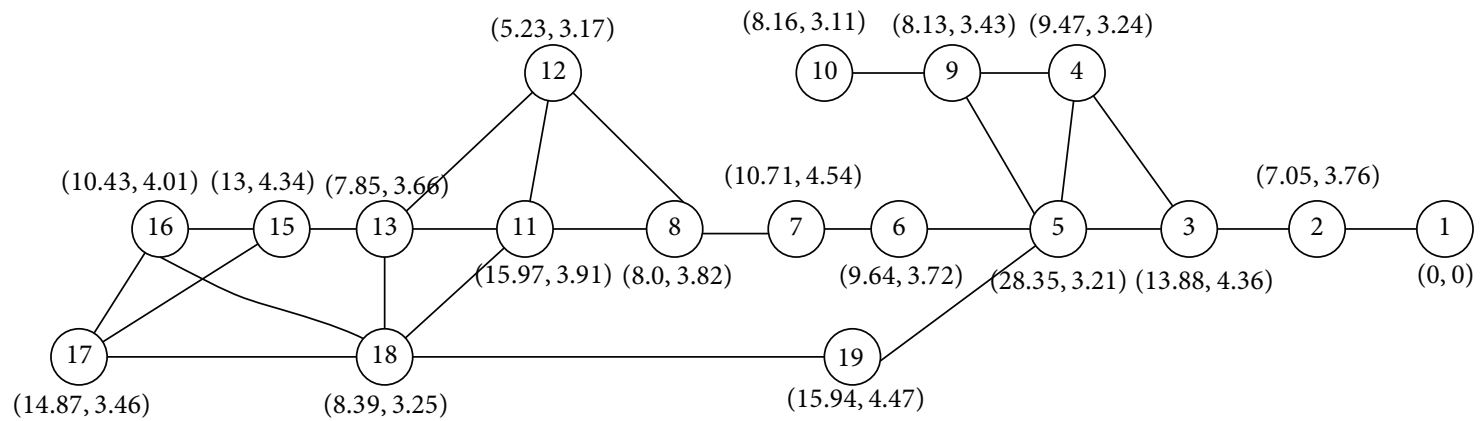

Index

(satisfaction degree and effective residence time)

FIGURE 11: Effective residence time and satisfaction degree.

TABLE 1: Tour time.

\begin{tabular}{lc}
\hline Tour time & Proportion (\%) \\
\hline$\leq 3$ & 45 \\
$>3$ & 55 \\
Total & 6 \\
\hline
\end{tabular}

Step 2: optimizing the $P_{2}$ level in objective function

$$
\min z_{2}=d_{2}^{+} \text {. }
$$

Step 3: Analysis of deviation: deviation index of satisfaction degree $\left(\sigma_{s}\right)$ and tour route distance $\left(\sigma_{d}\right)$ are defined and calculated.

Step 4: Based on the particle swarm optimization model, the priorities of the tour routes are calculated [17-19].

5.3. Sample. The distance and effective residence time are listed in Figures 10 and 11.

According to the questionnaire about tour route tourist, the number of visited attractions is between 7 and 17. The available routes are listed and categorized by the tour time as listed in Table 1.

It can be seen that 45 percent of the tourists' tour time is less than 3 times and $55 \%$ is larger than 3 hours. So the route which tour time is less than 3 hours is defined as quick tour and the route which tour time is larger than 3 hours is defined as depth tour.
The deviations of two routes are calculated, respectively, and listed in Table 2 and Table 3.

Deviation index of satisfaction degree $\left(\sigma_{s}\right)$ and tour route distance $\left(\sigma_{d}\right)$ are calculated. Deviation index of satisfaction degree is listed in Table 3. For the depth tour route, only when $\sigma_{s}$ is between 1 and 0.18 and $\sigma_{d}$ is between 0 and 0.104 , the route is the acceptable result. For the quick tour route, only when $\sigma_{s}$ is between 0 and 0.053 and $\sigma_{d}$ is between 0 and 0.172 , the route is the acceptable result.

The priory of the tour route is calculated and the suggested depth tour route and quick route are given, respectively, as shown in Figure 12.

Comparing the depth tour route with quick route, there are some differences among total number of the attraction, tour order, effective residence time, and so forth. For the suggested depth route, the total number is less than the quick tour route. Some attractions which are less famous are introduced so that the revisited tourists can experience and enjoy the tour route.

\section{Conclusion}

Conclusions can be given as follows.

A questionnaire about tourists' tour route and satisfaction was carried out and some information about the scene spot and tourists demand and tour behavior characteristic is concluded and analyzed. Visit frequency and effective residence time are positively correlated with satisfaction degree of the attraction. Comparing the tour budget time with real visiting 


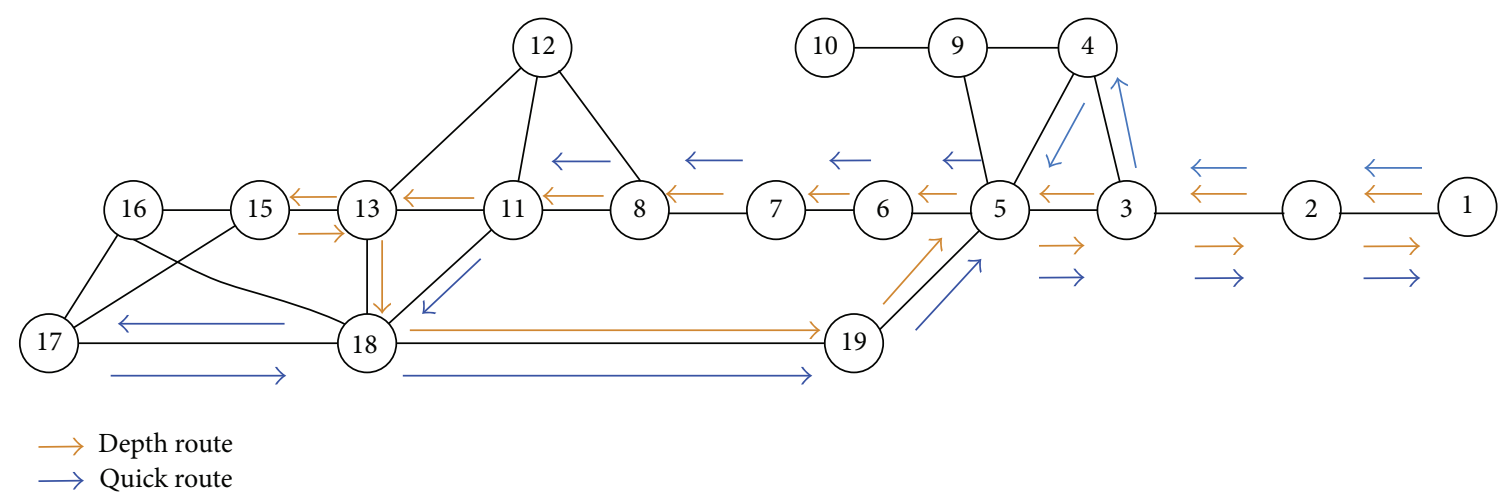

FIGURE 12: Suggested depth tour route and quick route.

TABLE 2: Parameter of depth tour and quick tour.

\begin{tabular}{lcccccc}
\hline & \multicolumn{2}{c}{ Satisfaction degree } & \multicolumn{2}{c}{ Distance } & \multicolumn{2}{c}{ Tour time } \\
& Depth tour & Quick tour & Depth tour & Quick tour & Depth tour & Quick tour \\
\hline Max. & 3.40 & 3.44 & 672.73 & 670.68 & 3.61 & 2.99 \\
Min. & 2.99 & 2.69 & 488.70 & 388.99 & 3.01 & 1.72 \\
\hline
\end{tabular}

TABLE 3: Deviation index of satisfaction degree.

\begin{tabular}{ccccc}
\hline & \multicolumn{2}{c}{$\sigma_{s}$} & \multicolumn{2}{c}{$\sigma_{d}$} \\
& Depth tour & Quick tour & Depth tour & Quick tour \\
\hline$\eta$ & 0.018 & 0.053 & 0.104 & 0.172 \\
\hline
\end{tabular}

time, it can be concluded that for about 30 percent of the tourists their real tour visiting time is less than their tour budget time.

Based on the convey datum, tour routes multiobjective optimization functions are prompted considering the tourists' behavior characteristics and psychological preferences. According to the distribution of the route time, the route which tour time is less than 3 hours is defined as quick tour and the route which tour time is larger than 3 hours is defined as depth tour. The priorities of the tour routes are calculated and the suggested depth tour route and quick route are given, respectively. The results show that visit frequency and effective residence time and tourists attractions satisfaction are positively correlated with satisfaction degree of the attraction.

Furthermore, during the tour route convey, it can be found that the congestion level of the attractions will affect the tourists' satisfaction degree. The more crowded the attraction is, the less satisfied the tourist feels. Also tourists will reduce the effective residence time in the crowded attractions and change their tour route under the information provided and distributed by the tourism enterprises. So the mechanism and influence of the congestion level on the tour route should be studied in the future.

\section{Conflict of Interests}

The authors declare that they have no conflict of interests regarding the publication of this paper.

\section{Acknowledgments}

This research was supported by National Basic Research Program of China (no. 2012CB725403) and the National Natural Science Foundation of China (Grant no. 51308015). The authors are very grateful for the comments from the anonymous reviewers. The authors would like to thank one anonymous referee for his (her) helpful comments and suggestion, which improved the content and composition substantially.

\section{References}

[1] R. A. Abbaspour and F. Samadzadegan, "Time-dependent personal tour planning and scheduling in metropolises," Expert Systems with Applications, vol. 38, no. 10, pp. 12439-12452, 2011.

[2] B. Jigang and C. Yifang, Geography of Tourism, vol. 42, Higher Education Press, Beijing, China, 1999.

[3] C. K. Campbell, An Approach to Research in Recreational Geography, Department of Geography, University of British Columbia, British Columbia, Canada, 1967.

[4] S. I. Stewart and C. A. Vogt, "Multi-destination trip patterns," Annals of Tourism Research, vol. 24, no. 2, pp. 458-461, 1997.

[5] J. Lundgren, "The development of tourist travel system: a metropolitan economic hegemony par excellence," Jahrbuch für Fremdenverkehr, pp. 62-65, 1972.

[6] R. L. Oliver, "A cognitive model of the antecedents and consequences of satisfaction decisions," Journal of Marketing Research, vol. 17, no. 4, pp. 460-469, 1980.

[7] L. R. Allen, H. R. Hafer, and P. T. Long, "Rural residents' attitudes toward recreation and tourism development," Journal of Travel Research, vol. 31, no. 4, pp. 27-33, 1993.

[8] P. T. Long, R. R. Perdue, and L. R. Allen, "Rural resident tourism perceptions and attitudes by community level of tourism," Journal of Travel Research, vol. 28, no. 3, pp. 3-9, 1990.

[9] S. J. Calver and S. J. Page, "Enlightened hedonism: exploring the relationship of service value, visitor knowledge and interest, to 
visitor enjoyment at heritage attractions," Tourism Management, vol. 39, pp. 23-36, 2013.

[10] J. L. McElroy, P. Tarlow, and K. Carlisle, "Tourist harassment: review of the literature and destination responses," International Journal of Culture, Tourism and Hospitality Research, vol. 1, no. 4, pp. 305-314, 2007.

[11] M. Abou-Zeid and M. Ben-Akiva, "The effect of social comparisons on commute well-being," Transportation Research A, vol. 45, no. 4, pp. 345-361, 2011.

[12] D. Kahneman and A. Tversky, "Prospect theory: an analysis of decision under risk," Econometrica, vol. 47, no. 2, pp. 263-291, 1979.

[13] E. Avineri and P. H. L. Bovy, "Identification of parameters for a prospect theory model for travel choice analysis," Transportation Research Record, vol. 2082, pp. 141-147, 2008.

[14] T. Pedersen, P. Kristensson, and M. Friman, "The focusing illusion in travel mode preference: effects of critical incidents on car users' predicted satisfaction with public transport," in Proceedings of the 12th International Conference on Travel Behavior Research, Jaipur, India, December 2009.

[15] R. Prentice, "Community-driven tourism planning and residents' preferences," Tourism Management, vol. 14, no. 3, pp. 218227, 1993.

[16] H. Yan and G. Hongzhi, "Study on models of commuter mode choice beyond fuel prices based on ordered logit models," Journal of American Science, vol. 6, no. 8, pp. 230-235, 2010.

[17] H. F. Lewis and T. R. Sexton, "On the tour partitioning heuristic for the unit demand capacitated vehicle routing problem," Operations Research Letters, vol. 35, no. 3, pp. 374-378, 2007.

[18] W. Souffriau, P. Vansteenwegen, J. Vertommen, G. V. Berghe, and D. V. Oudheusden, "A personalized tourist trip design algorithm for mobile tourist guides," Applied Artificial Intelligence, vol. 22, no. 10, pp. 964-985, 2008.

[19] M. Gong, L. Jiao, D. Yang, and W.-P. Ma, "Research on evolutionary multi-objective optimization algorithms," Journal of Software, vol. 20, no. 2, pp. 271-289, 2009. 


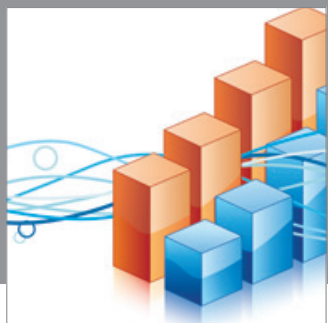

Advances in

Operations Research

mansans

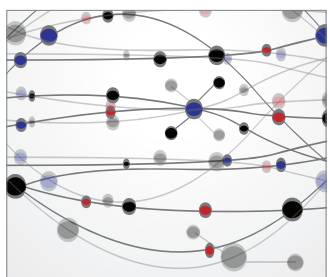

The Scientific World Journal
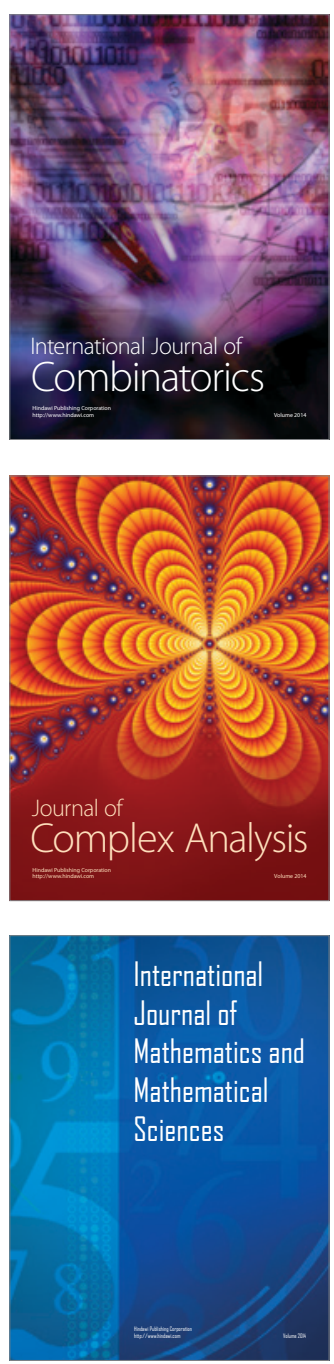
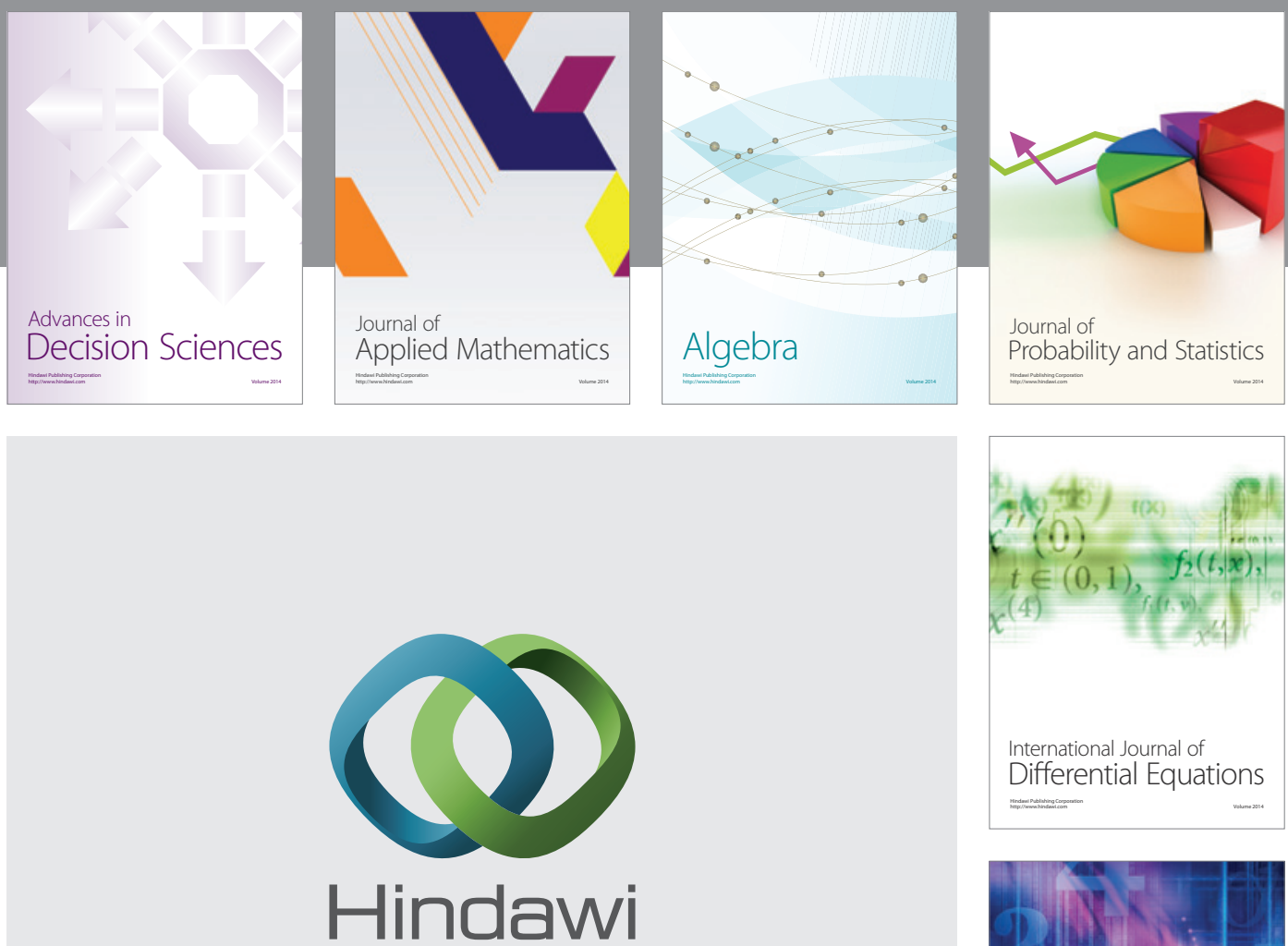

Submit your manuscripts at http://www.hindawi.com
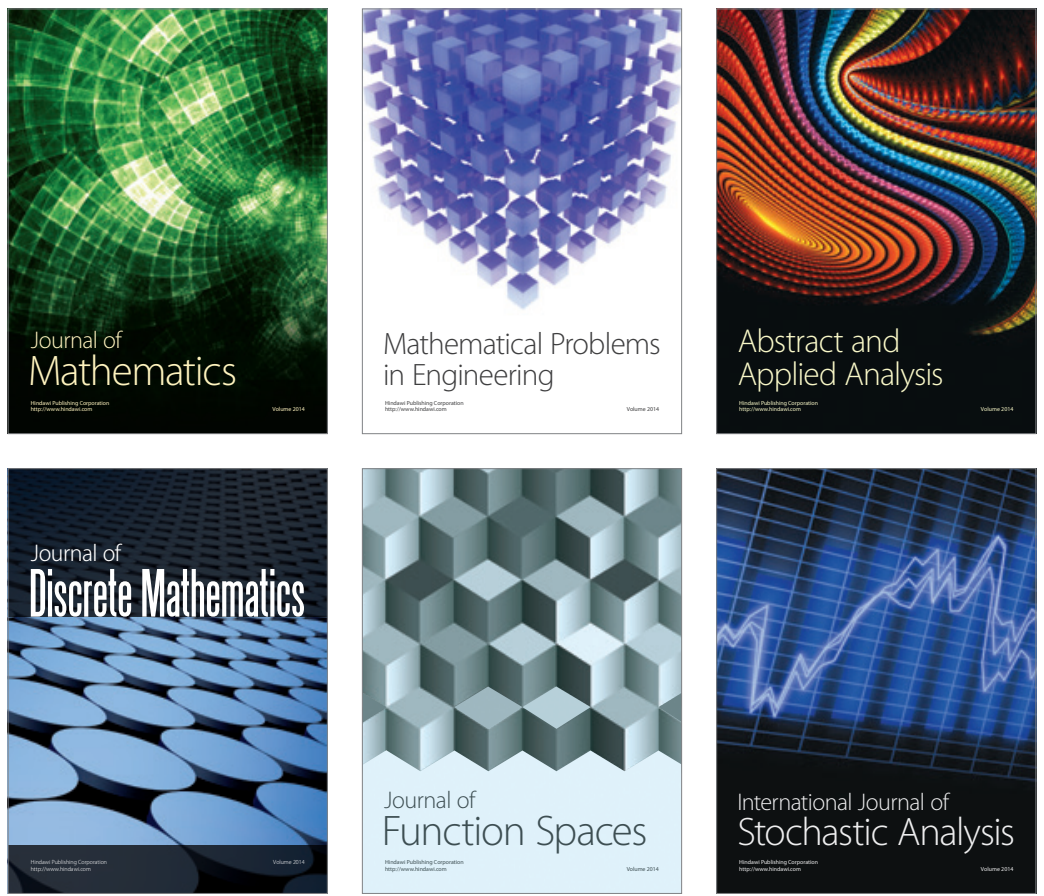

Journal of

Function Spaces

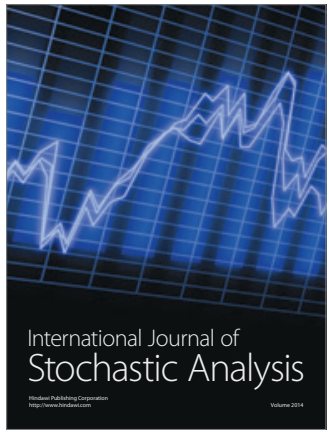

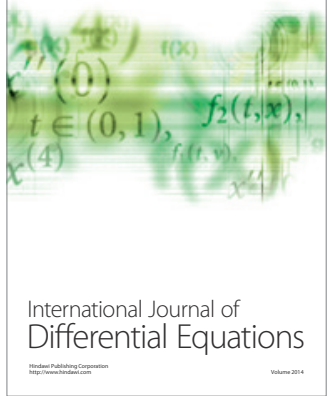
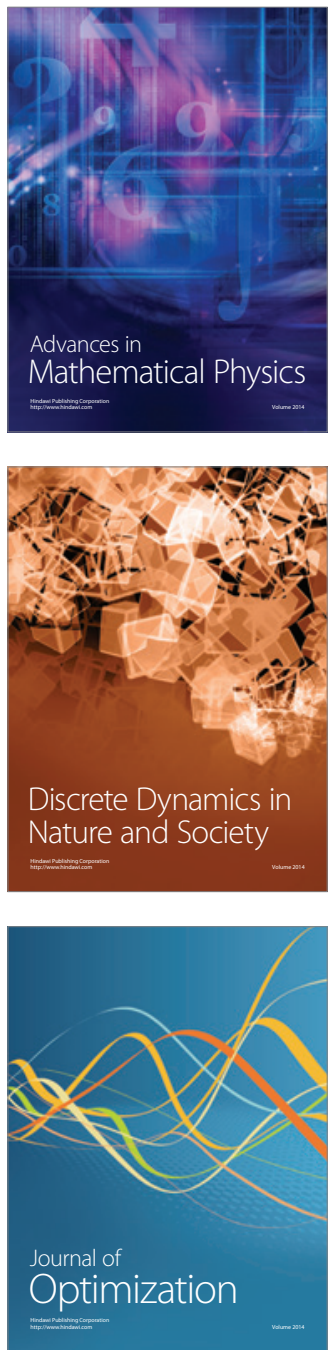